Florida International University FIU Digital Commons

\title{
Relationship between a middle school band director's attire and incidences of student off-task behaviors in the classroom
}

Josephine Camacho

Florida International University

DOI: $10.25148 /$ etd.FI14052549

Follow this and additional works at: https://digitalcommons.fiu.edu/etd

Part of the Music Commons

\section{Recommended Citation}

Camacho, Josephine, "Relationship between a middle school band director's attire and incidences of student off-task behaviors in the classroom" (2005). FIU Electronic Theses and Dissertations. 1985.

https://digitalcommons.fiu.edu/etd/1985 
FLORIDA INTERNATIONAL UNIVERSITY

Miami, Florida

RELATIONSHIP BETWEEN A MIDDLE SCHOOL BAND DIRECTOR'S ATTIRE AND INCIDENCES OF STUDENT OFF-TASK BEHAVIORS IN THE CLASSROOM

A thesis submitted in partial fulfillment of the

requirements for the degree of

MASTER OF SCIENCE

in

MUSIC EDUCATION

by

Josephine Camacho

2005 
To: Interim Dean Mark Szuchman

College of Arts and Sciences

This thesis, written by Josephine Camacho, and entitled Relationship between a Middle School Band Director's Attire and Incidences of Student Off-task Behaviors in the Classroom, having been approved in respect to style and intellectual content, is referred to you for judgment.

We have read this thesis and recommend that it be approved.

Roby George

Barry Greenberg

Carotyn Failton, Major Professor

Date of Defense: June 20, 2005

The thesis of Josephine Camacho is approved.

Interim Dean Mark Szuchman

Cottege of Arts and Sciences

Dean Doxglas Wartzok

University Graduate School

Florida International University, 2005 


\section{DEDICATION}

I dedicate this thesis to my loving husband, Manuel. I could not have done this without your unyielding support and patience. You are the sails of my ship. Thank you for always keeping me strong. 


\section{ACKNOWLEDGMENTS}

First, I wish to thank the members of my committee for their support and guidance. Dr. Roby George, your enthusiasm and genuine interest in my ideas was a great motivator. Dr. Barry Greenberg, your Research in Education class was the key to my successful study. Without you believing in my little idea, this entire study would not have happened. Dr. Carolyn Fulton, the head of my thesis committee, thank you for always believing in me, and challenging me so that I may reach my fullest potential.

To my wonderful parents, there are no words great enough to thank you for your unconditional love and support. And finally, I would like to thank my sister, Concetta, for listening to me, reading my rough drafts, and giving me some of the best feedback I ever received. 


\begin{abstract}
OF THE THESIS
RELATIONSHIP BETWEEN A MIDDLE SCHOOL BAND DIRECTOR'S ATTIRE AND INCIDENCES OF STUDENT OFF-TASK BEHAVIORS IN THE CLASSROOM by

Josephine Camacho

Florida International University, 2005

Miami, Florida

Professor Carolyn Fulton, Major Professor

The purpose of this study was to examine whether a middle school band director's attire had an effect on off-task student behaviors in his classroom. One male middle school band director participated and three of his classes were observed. The study lasted twenty days and consisted of three treatments (casual attire, business casual attire, and formal business attire). A tally sheet was used to determine the number of off-task behaviors per student per minute. The results indicated that in this classroom, the students (of all three classes) were off-task less often when the band director wore business casual attire. This was the clothing that he wore consistently from the beginning of the school year. Straying from this consistency made off-task behaviors in the classroom rise. The most off-task behaviors occurred when the band director wore casual clothing. Off-task behaviors also rose when the band director wore business formal attire.
\end{abstract}




\section{TABLE OF CONTENTS}

CHAPTER

PAGE

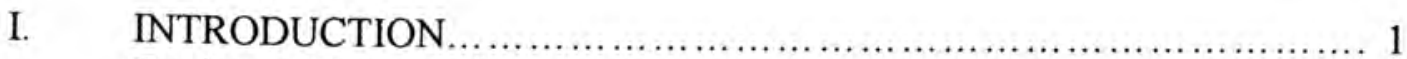

Review of Related Literature ....................................... 1

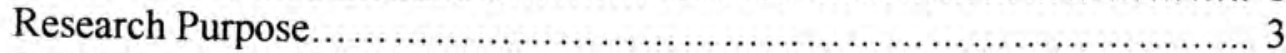

Statement of the Hypothesis.................................................. 3

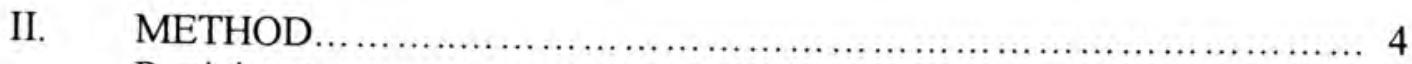

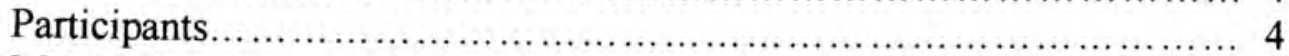

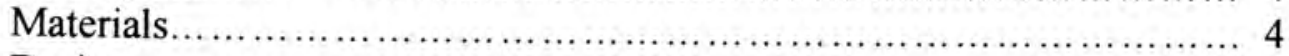

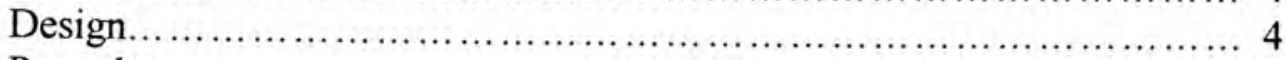

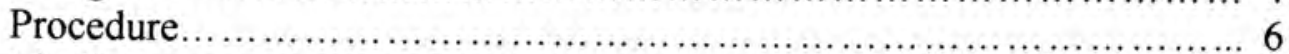

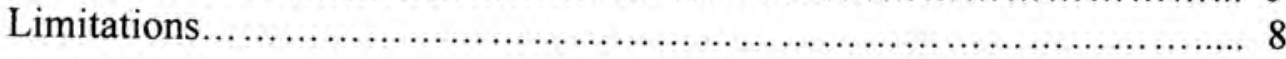

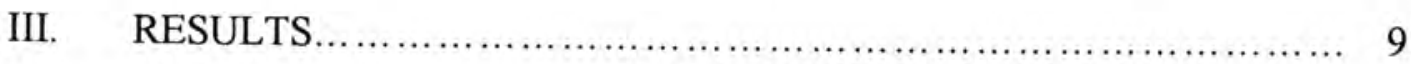

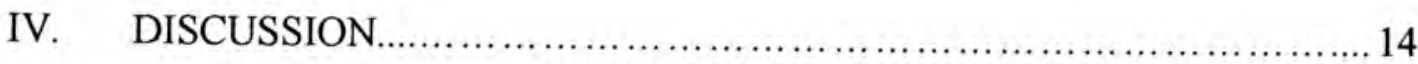

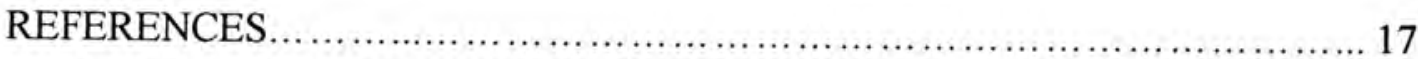

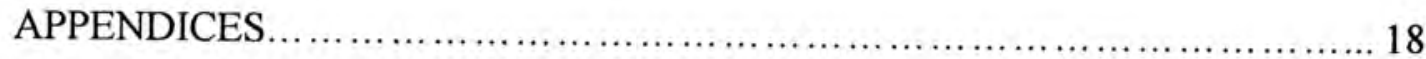


One of the most common concerns for the music educator is classroom discipline. The middle school band room is a unique environment in which students must work together to make music. This can be a fun, challenging, and enlightening experience, but without good classroom management it could become stressful for the teacher and the students. The band director is in a unique position of having to create discipline and focus in an exciting and social activity (making music on instruments). There is considerable literature in the music education field which stresses the importance of nonverbal cues and body language for success in the music classroom such as proxemics (the physical distance between teacher and students), postures, gestures, facial expressions, and eye behavior (Hughs, 1981; Gordon, 2001). Clothing, however, which is a nonverbal cue, is rarely mentioned.

With the amount of information on clothing and perception, it seems strange that teacher clothing has not been investigated nearly as much as it should. With the knowledge that clothing is a means of expression and a complex mode of communication, it seems only natural that all teachers should be aware of what they might be communicating through their clothing (Damhorst, 1990). Review of Related Literature

How a person dresses is a direct reflection of a choice the wearer makes. It is the way a person wants to be seen. It is an image one conveys. Clothing is a complex mode of nonverbal communication (Damhorst, 1990). However, what is unknown is how much information a person can successfully convey through what they wear, and if they are perceived the way they want to be. Also, a person's clothes can determine the way they 
will be treated in different social contexts (Damhorst, 1990; Simmons, 1996; Davis, Clarke, Francis, et al., 1992; Morris, Gorham, Cohen, \& Huffman, 1996).

There have been relatively few studies conducted that examine the relationship between what people wear and how they will be treated. Some studies found that people treat other people more positively when they are dressed similarly to themselves (Reid, Lancuba, \& Morrow, 1997; Morris, Cohen, \& Huffman, 1996). This result implies the idea that if a person is dressed like yourself, they may share other interests and could be your friend.

A few things have been understood about clothes and a first impression. Clothes have a high effect on people's perception of other people's sociability, approachability, competence, expertness, legitimacy, and power (Conner, Peters, \& Nagasawa, 1975; Workman, \& Johnson, 1989; Temple, \& Loewen 1993; Kwon, \& Johnson-Hillery, 1998). This may be very relevant to the education profession in regards to how students perceive their teachers and how other people view the teaching profession in general. Interestingly, studies have been inconsistent regarding how much of a person's intelligence can be perceived by what a person wears (Conner, Peters, \& Nagasawa, 1975).

Within the limited research that has been done in teacher attire, most has focused on student initial perceptions of teacher character traits, or first impressions, by using doctored photographs and other such methods (Davis, Clarke, Frances, et al. 1992; Morris, Gorham, Cohen, \& Huffman, 1996; Lukavsky, Butler, \& Harden, 1995; Butler, \& Roesel, 1989). A majority of studies have found that the more formal business attire a teacher wears, the more positive responses they receive in respect and power, but conversely they also receive the least positive response for approachability (Davis, Clarke, 
Frances, et al. 1992; Morris, Gorham, Cohen, \& Huffman, 1996; Lukavsky, Butler, \& Harden, 1995; Butler, \& Roesel, 1989). This creates an issue because educators want to portray power and authority in their classrooms, but not to the point where students feel they cannot approach teachers with questions or issues they may be facing.

\section{Research Purpose}

The purpose of this study was to investigate the relationship between a middle school band director's attire and the incidences of off-task student behavior in the classroom. Off-task student behavior was defined as students talking out of turn, playing on their instrument when not instructed to do so, distracting the director, and/or purposely hindering the learning of a fellow student.

Statement of the Hypothesis

Understanding that nonverbal communication is an important tool in the music classroom, and in all classrooms, it seemed natural that the effects of a teacher's clothing in the classroom be examined for their communicative powers. Knowing that studies have shown there to be positive correlations between a person in formal business dress and a perception of power and competence, it was hypothesized that student off-task behaviors would decrease as director attire formality increased. 
Participants

A volunteer male middle school band director from Miami-Dade County Public Schools participated in the study. Three of his classes were observed; one in the morning (A), one mid-day (B), and the last class of the afternoon (C). All students wore a school uniform consisting of a choice of navy or khaki slacks (no jeans), navy or khaki skirt to the knee, red or teal polo shirt, and regular shoes or sneakers (no sandals).

\section{Materials}

Physical observations were made by the researcher using a system based off the Flanders Interaction Analysis Categories system, structured to meet the needs of this study. The band director supplied five days worth of casual clothing, five days worth of business casual clothing, and five days worth of business formal attire. A camera was used to document an example of the band director in each style of dress. At the conclusion of the study, a questionnaire was given to the students for feedback on their opinions on teacher attire.

\section{Design}

The design used for this study was a counterbalanced design but instead of rotating the treatment order for each class, each class experienced the same treatment order. This was necessary because it would have required the band director to change into three different styles of clothing per day, or if he remained in one style per day, then only one class per day would be observable. To get through the three different classes with different treatment orders where the band director could stay in one outfit for the day would have required another thirty school days. This was impractical; therefore, each 
class received the same treatment order, and observations could be made of all three classes on each day of the experiment. Each of the three classes used were as equivalent as possible. All three were beginning bands with a mixture of predominately sixth and seventh grade boys and girls. Class A consisted of 15 students. Class B consisted of 19 students. Class $\mathrm{C}$ consisted of 15 students. Some days class sizes varied due to children absent from school or school activities which required a student to be missing from class, but no day was used where the band director was not teaching the class as an ensemble. Observations were conducted during treatments.

Treatment $1(\mathrm{X})$ was casual attire which was defined as sneakers, jeans, and a tshirt with or without an opened button down shirt worn over the t-shirt. Treatment 2 (Y) was business casual attire which was defined as shoes (no sneakers), khaki pant, longsleeved button-down shirt tucked in with a belt. Treatment $3(\mathrm{Z})$ was business formal attire which was defined as dress shoes, slacks or suit pant, long-sleeved button-down shirt tucked in, tie, and sport coat or suit coat. 
Figure 1. Example of each treatment attire.

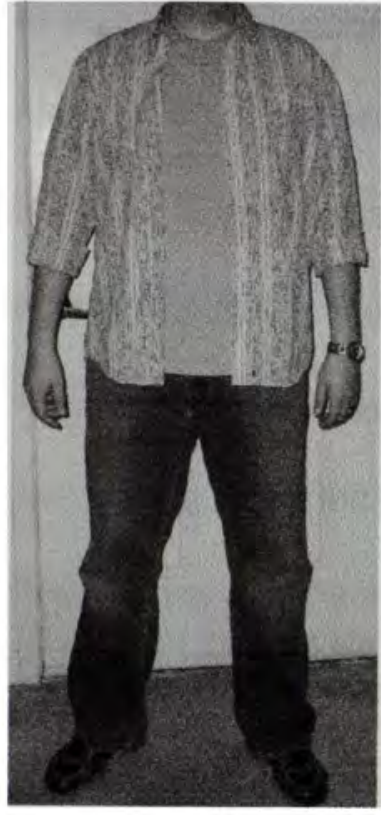

Treatment X

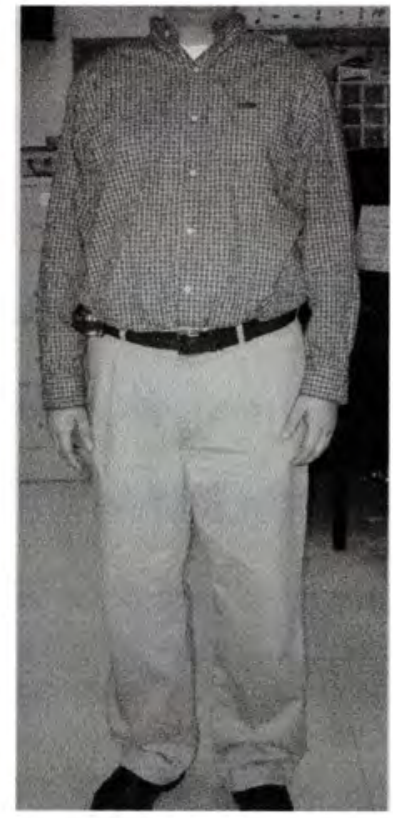

Treatment Y

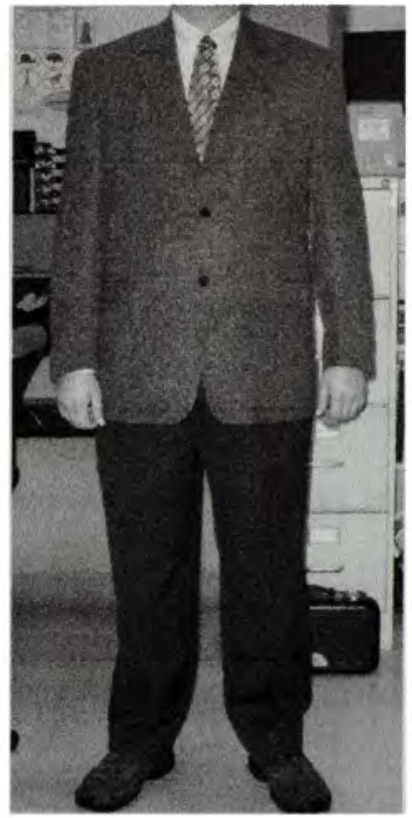

Treatment $\mathbf{Z}$

\section{Procedure}

During January of 2005, one male middle school band director volunteered to participate in this study. He was given a list of appropriate clothing for each category of attire and time enough to prepare and get each outfit approved by the researcher. The three class periods observed were first period, third period, and sixth period, so that the time of day would not be a factor.

The study was designed to last twenty school days. The twenty days were split into four blocks of five days each. These twenty days were not consecutive. Days in which any of the classes to be observed could not function like usual (i.e. holidays, half days, school assembly days, etc.) were not used. The study began on February 7, 2005 and ended on April 18, 2005. 
The first block of five days was critical in allowing the researcher time to adjust to making observations and using the tally sheet. No treatment was given during the first block. During this time, the band director informed the researcher on what he considered to be off-task behavior. For example, at first the researcher would mark down every time a student spoke to another student while the teacher was working with others. As the initial observation days progressed, the researcher noticed that sometimes a student who was talking while the teacher was working with others was not off-task, but may have been asking a fellow student for advice in the music, such as correct fingerings or where to breathe. In this case, she is on-task. By the end of the five days, the researcher felt confident that observations were as accurate and consistent as possible.

The second block of five days was treatment $\mathrm{X}$. The third block of five days was treatment $Y$, and the final block of five days was treatment $\mathrm{Z}$. During treatments, the band director was instructed to do nothing different from the way he normally taught and disciplined. The observer did not interact with the director or any of the students during observations and was seated at the front left of the director in a desk. Students were not aware that the way their band director was dressing was connected to the observer. The students were informed that the observer was watching the band director as part of a thesis paper for the university prior to the study.

Numerals indicating different behaviors were used on the tally sheet (example of tally sheet is located in Appendix A): 1 = talking out of turn, 2 = playing on instrument out of turn, and $3=$ other off-task behaviors. The most common reasons for marking a 3 was when a student was refusing to participate (sitting idly) or when a student was touching another student's instrument. For each class, a start time and end time were 
documented as well as the number of students in the class that day. The total number of off-task behaviors were counted and divided by the number of students in class that day to create the number of off-task behaviors per student. Then, the number of instructional minutes observed was divided by the number of off-task behaviors per student to get the number of off-task behaviors per student per minute for that class that day. For example, if there were 15 students and 18 off-task behaviors recorded in an observational span of 50 minutes, then the math would be $18 / 15=1.2$ (off-task behaviors per student). Then, $1.2 / 50=.024$ (off-task behaviors per student per minute or BSM). It is this last number (BSM) on which this study will concentrate.

At the conclusion of the study, a questionnaire was given to the students to gain some insight on how they view the importance of teacher attire. The students were instructed to think about the questions, take their time, and answer honestly without looking at other students papers. The questionnaire consisted of eight questions. Half were yes, no, or sometimes questions, and the other half were open-ended response questions. At the top of the questionnaire, students circled what grade they were in and their gender.

\section{Limitations}

As previously mentioned, a counterbalanced design was used, but without varying treatment orders due to time constraints. Ideally, each group should have received different treatment orders to correct for treatment order interference. It was presumed that exposure to one treatment would not affect the effectiveness of another. Also, only one teacher served as the experimental condition. Future research must be done to verify if the results would be the same on other subjects. 
Results

During treatment X, Class A had an average of .0408 BSM. Class B had an average of .0368 BSM. Class C had an average of .0478 BSM. During treatment Y, Class A had an average of .0238 BSM. Class B had an average of .0204 BSM. Class C had an average of .0332 BSM. During treatment Z, Class A had an average of .0292 BSM. Class $\mathrm{B}$ had an average of $.0260 \mathrm{BSM}$. Class $\mathrm{C}$ had an average of .0358 BSM. In Figure 2, we see how each class responded to each of the treatments. Notice that each class shares the same pattern. During treatment $\mathrm{X}$, off-task behaviors are high. During treatment $\mathrm{Y}$, the off-task behaviors decrease. Finally, during treatment $Z$, off-task behaviors go up again, but not at the level of treatment $\mathrm{X}$.

The average BSM for treatment $\mathrm{X}$ of all three classes was .0418 . The average BSM for treatment $Y$ of all three classes was .0258 . The average BSM for treatment $Z$ of all three classes was .0302 . 
Figure 2. Average off-task behaviors per student per minute (BSM) during each treatment.
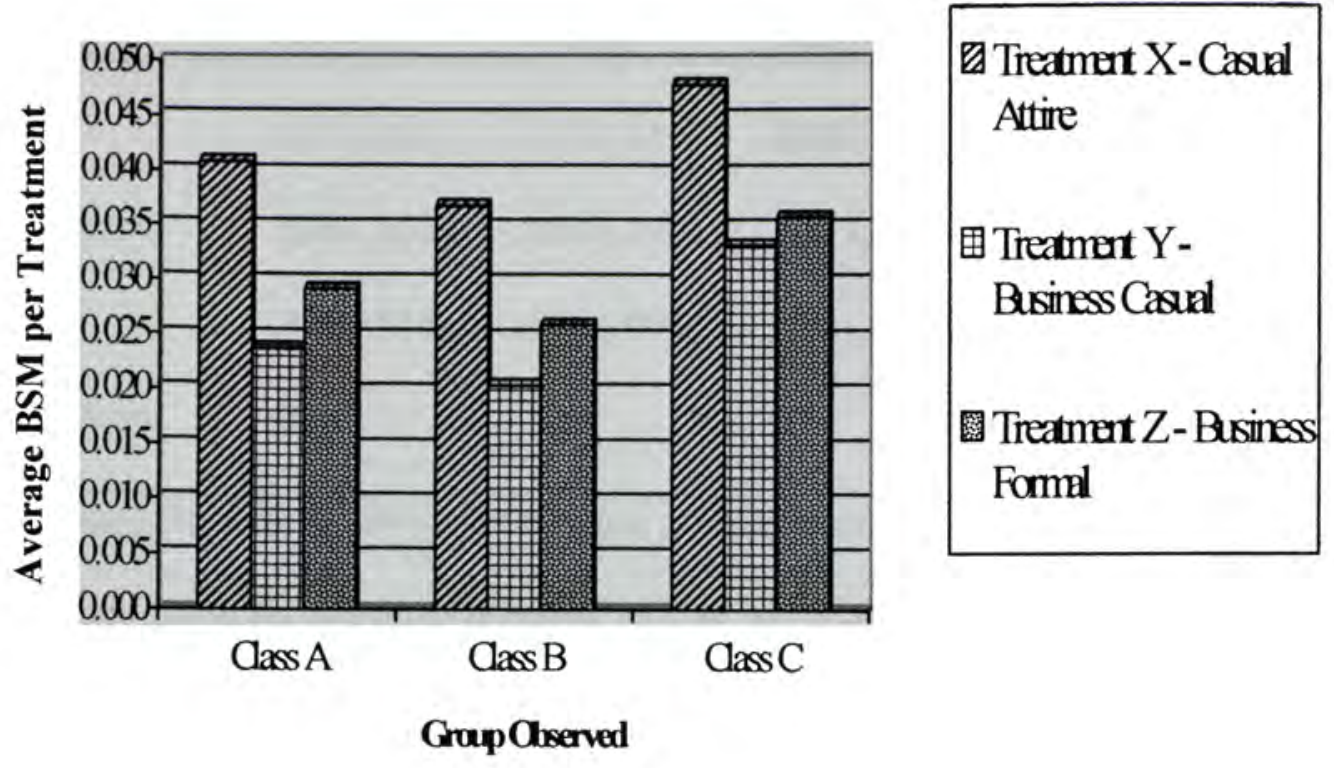

GroupChsenved

An examination of the relationships between the BSM of each class during each treatment was conducted using a $3 \times 3$ between-within analysis of variance. Table 1 represents the cell means and standard deviations. For the omnibus test of class, the Greenhouse-Geisser sphericity correction was applied to the degrees of freedom. The Greenhouse-Geisser estimate of epsilon was 0.85 .

The main effect of class was statistically significant at $F(1.69,20.32)=4.44, p$ $=.03$. Follow-up pairwise comparisons were conducted both with and without using the Holm's Sequential Bonferonni method to control for Type I error. Results were comparable in both scenarios. Tests revealed that Class $\mathrm{C}$ engaged in significantly more off-task behaviors than Class B. 
Table 1. Average off-task behaviors per student per minute (BSM), Standard Deviations and sample size as a function of Class period and Dress.

\begin{tabular}{lllll} 
& Class A & Class B & Class C & Marginal Mean \\
\hline Casual & $.041(.021)$ & $.037(.014)$ & $.048(.018)$ & .042 \\
Business Casual & $.024(.005)$ & $.020(.010)$ & $.033(.009)$ & .026 \\
Formal & $.029(.014)$ & $.026(.005)$ & $.036(.013)$ & .030 \\
Marginal Mean & .031 & .028 & .039 & .033 \\
\hline
\end{tabular}

Note: Standard Deviations are in parentheses; $n=5$ per group

When testing for the main effect of teacher attire $[F(2,12)=3.38, p=.069]$, the effect was not found to be statistically significant (because $p>.05$ ). However, the effect is approaching significance; therefore, follow-up pairwise comparisons were performed both with and without using the Holm-Sequential Bonferonni Method as exploratory analysis. It was discovered that students were off-task significantly more $[t(1)=2.67, p$ $=.027]$ when the band director wore casual clothes than when he wore business casual clothes (not applying the correction for Type I error).

The results of the questionnaire were divided by grade level and gender. The students who took the questionnaire consisted of eight sixth grade females, 12 sixth grade males, five seventh grade females, 19 seventh grade males, and one eighth grade female. The most popular answers to each question for sixth graders are noted in Table 2, along with the percentage of students in each gender who responded in that way. Table 3 shows how seventh graders responded. The single eighth grade girl was left off the tables because she was the only eighth grader to take the questionnaire. 
Table 2. Most common answers of questionnaire given by sixth grade females $(6 \mathrm{~F})$ and males $(6 \mathrm{M})$.

$$
6 \mathrm{~F}
$$

No

Yes

$\%$

50

No

50

to the way your teachers dress?

2. Do you believe that it is important for your teacher to dress appropriately?

3. What do you believe is appropriate teacher clothes?

4. What kind of clothes do you think a teacher should $\underline{\text { not }}$ wear?

5. Have you noticed that your band teacher has been dressing in different ways lately?

6. What did you think when your band teacher wore jeans and a t-shirt to school?

7. What did you think when your band teacher wore a suit to school?

Nice Shirt/Blouse

Anything too short/

short pants/shorts/

mini-skirts

Yes

88

$$
\text { Yes }
$$

63 Sleeveless Shirt/tank top/ 25 spaghetti straps

He looked relaxed/ comfortable

He had something important to do after school. cool.

50 He had a concert or meeting. He was more serious. I did not notice.

8. Do you think you act differently No when your band teacher wears different clothes? 
Table 3. Most common answers of questionnaire given by seventh grade females (7F) and males (7M).

$7 \mathrm{~F}$

Sometimes

Yes

60

Yes

53

important for your teacher to

dress appropriately?

3. What do you believe is appropriate teacher clothes?

4. What kind of clothes do you think a teacher should $\underline{\text { not }}$ wear?

5. Have you noticed that your band teacher has been dressing in different ways lately?

6. What did you think when your band teacher wore jeans and a t-shirt to school?

7. What did you think when your band teacher wore a suit to school?

Anything low cut/ showing too much skin/ jeans/too baggy/lazy/ bright/beachy (sandals)

Jeans

40

Jeans

Yes

Yes

58

He had a meeting. He did $40 \quad$ I did not notice.

26 something good/won something.

8. Do you think you act differently No 40 when your band teacher wears different clothes? 


\section{Discussion}

It was hypothesized, based on studying previous research on first impressions, that as the teacher's attire formality increased, students would be more respectful and less off-task. This was only partially true. Most researchers in the past have focused on the two extremes; very casual attire versus very formal attire. When looking at these two extremes in this study, it was also concluded that business formal attire (wearing a suit) produced a better behaved classroom response than casual attire (jeans and a t-shirt); however, the middle ground, which would be a business casual look (khaki pant and a long sleeved button down shirt), became the most important aspect of this study. The lowest occurrences of off-task behaviors happened during business casual attire, not business formal attire. Although no statistical significance between the different styles of dress over all was found, there was statistical significance between casual and business casual attire, and all three classes observed responded similarly to each treatment. The rest of the results were close to significance $(p=.069)$. In the future, longer observation periods and more than one observer (if possible) would be recommended in order to have more reliable results.

When we examine these results, we must focus on why the business casual attire was the most successful. First, it is important to remember that this study was done after the students had already known this teacher for over four months. During the time prior to the study, an image of their band director had already been formulated in their minds. This particular band director's usual attire was business casual. He rarely strayed from this, and this was the way the students were used to seeing him. 
The issue of consistency then becomes the next variable to consider in further studies. It is logical to suggest that when the teacher breaks the pre-set image of what the students expect to see, they become more easily distracted and are more likely to get offtask more frequently, but further research would be necessary to verify this.

The questionnaire was given to see if students were aware that their behavior may be influenced by their teacher's appearance. From the responses given, it was apparent that students do pay attention to what their teachers wear and have certain expectations of what is and is not appropriate teacher attire. Although the students admit to paying attention to the way their teachers dress, it was interesting to see that most students believe strongly that their teacher's clothes has no impact on their behavior. This was not unusual, as no one, including an adult, wants to believe that their own behavior could be affected by such seemingly inconspicuous things.

This study should be replicated with band directors who normally dress casual or formal. The treatment order should be conducted in such a way that the teacher's normal style of dress would be the second treatment to see if the same pattern of off-task behaviors per student per minute would occur. Further research should also be done on female band directors to see if the same results would occur across gender. Changing the location of this experiment to a high school, elementary school, and/or college would be beneficial as well.

For any band director or general teacher who is interested in continually striving to create the perfect classroom environment, information on ideal clothing is extremely useful. If an educator can know that there is a style of dress or a consistency in dress that 
is ideal for his classroom, then it could be the easiest and quickest way to make at least one improvement in his classroom environment. 
Butler, S., \& Roesel, K. (1989). The influence of dress on students' perceptions of teacher characteristics. Clothing and Textiles Research Journal, 7(3), 57-59.

Conner, B. H., Peters, K., \& Nagasawa, R. H. (1975). Person and costume: Effects on the formation of first impressions. Home Economics Research Journal, 4(1), 32-41.

Damhorst, M. L. (1990). In search of a common thread: Classification of information communicated through dress. Clothing and Textiles Research Journal, 8(2), 1-12.

Davis, B., Clarke, A. R. B., Francis, J., et al. (1992). Dress for respect: The effect of teacher dress on student expectations of deference behavior. The Alberta Journal of Educational Research, 38(1), 27-31.

Gordon, D. G. (2001). Classroom management: Problems and solutions. Music Educators Journal, 88(2), 17-23.

Hughs, J. R. (1981). How do you behave? Your nonverbal actions are critical to student motivation. Music Educators Journal, 67(5), 52-53.

Kwon, Y., \& Johnson-Hillery, J. (1998). College students' perceptions of occupational attributes based on formality of business attire. Perceptual and Motor Skills, 87, 987-994.

Lukavsky, J., Butler, S., \& Harden, A. J. (1995). Perceptions of an instructor: Dress and students' characteristics. Perceptual and Motor Skills, 81, 231-240.

Morris, T. L., Gorham, J., Cohen, S. H., \& Huffman, D. (1996). Fashion in the classroom: Effects of attire on student perceptions of instructors in college classes. Communication Quarterly, 45(2), 135-148.

Reid, A., Lancuba, V., \& Morrow, B. (1997). Clothing style and formation of first impressions. Perceptual and Motor Skills, 84, 237-238.

Simmons, B. J. (1996). Teachers should dress for success. Clearing House, 69(5), $297-$ 298.

Temple, L. E., \& Loewen, K. R. (1993). Perceptions of power: First impressions of a woman wearing a jacket. Perceptual and Motor Skills, 76, 339-348.

Workman, J. E., \& Johnson, K. K. P. (1989). The role of clothing in extended inferences. Home Economics Research Journal, 18(2), 164-169. 
Appendix A

Example of the tally sheet used for each day of the experiment.

J. Camacho

A/X2/04/14

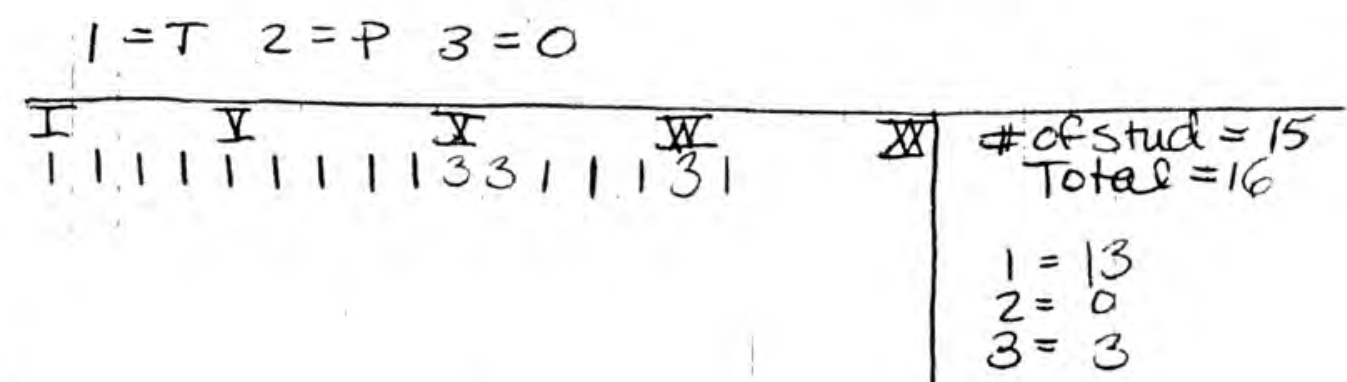

(A)

(B)

In $1, \Gamma_{1111} T_{33}$

(c)

$$
4 / 5 / 05
$$

XXX $\begin{gathered}\text { \# of stud }=15 \\ \text { Total =16 } \\ 1=13 \\ 2=0 \\ 3=3\end{gathered}$

$$
\begin{aligned}
\text { Start } & =8: 45 \\
\text { Emo } & =9: 32
\end{aligned}
$$

$$
\text { Xx. } \begin{gathered}
\text { \#ofstud }=19 \\
\text { Total }=12 \\
1=10 \\
2=0 \\
3=2 \\
\text { Start }=10: 40 \\
\text { End }=11: 29
\end{gathered}
$$

\#21 of 5 thud $=12$ Total $=1$

$$
\begin{aligned}
& 1=13 \\
& 2=3 \\
& 3=1
\end{aligned}
$$

$$
\begin{aligned}
\text { Start } & =2: 10 \\
\text { End } & =2: 59
\end{aligned}
$$

18 


\section{Appendix B}

Example of the questionnaire given to the students at the end of the study.

Circle Appropriate Response:

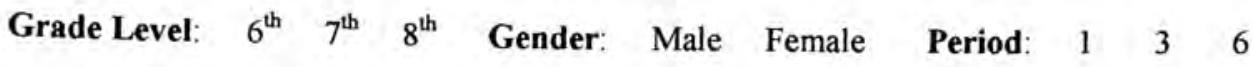

Think about the questions, take your time, and be honest with your responses!

1. Do you ever pay attention to the way your teachers dress?

2. Do you believe that it is important for your teacher to dress appropriately?

3. What do you believe is appropriate teacher clothes?

4. What kind of clothes do you think a teacher should not wear?

5. Have you noticed that your band teacher has been dressing in different ways lately?

6. What did you think when your band teacher wore jeans and t-shirts to school?

7. What did you think when your band teacher wore a suit to school?

8. Do you think you act differently when your band teacher wears different clothes?

(If you need more space to write an answer, use the back, but make sure you put the question \# next to your response.) 